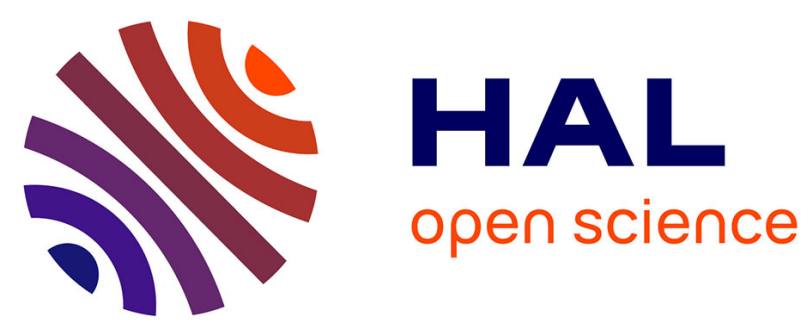

\title{
Innovative products and services with environmental benefits: design of search strategies for external knowledge and absorptive capacity
} Caroline Mothe, Uyen Nguyen-Thi, Angela Triguero-Cano

\section{- To cite this version:}

Caroline Mothe, Uyen Nguyen-Thi, Angela Triguero-Cano. Innovative products and services with environmental benefits: design of search strategies for external knowledge and absorptive capacity. Journal of Environmental Planning and Management, In press, 10.1080/09640568.2017.1372275 . hal01701063

\section{HAL Id: hal-01701063 \\ https://hal.univ-smb.fr/hal-01701063}

Submitted on 5 Feb 2018

HAL is a multi-disciplinary open access archive for the deposit and dissemination of scientific research documents, whether they are published or not. The documents may come from teaching and research institutions in France or abroad, or from public or private research centers.
L'archive ouverte pluridisciplinaire HAL, est destinée au dépôt et à la diffusion de documents scientifiques de niveau recherche, publiés ou non, émanant des établissements d'enseignement et de recherche français ou étrangers, des laboratoires publics ou privés. 


\title{
Innovative products and services with environmental benefits: design of search strategies for external knowledge and absorptive capacity
}

\begin{abstract}
Although the antecedents of environmental innovation and open innovation strategies have been well studied separately, the relationship between a firm's openness and environmental technological innovation still remains an interesting topic to research, especially in terms of the various modes of openness on the one hand and the product-process distinction on the other. This study relies on data from the French Community Innovation Survey to differentiate the association of three dimensions of open inbound innovation search strategies-acquiring, sharing, and information sourcing-with environmental product (ecoproduct) and process (ecoprocess) innovations. Inbound innovation, attained through the acquisition of machinery, equipment, and software, is more likely to be associated with ecoprocess than ecoproduct innovations; external R\&D only drives ecoproducts. Inbound sharing through R\&D cooperation seems associated with the introduction of both ecoproducts and ecoprocesses. For inbound innovation sourcing, external market sources of information are positively associated with firms' involvement in all types of environmental innovation.
\end{abstract}

Keywords: Environmental innovation; Inbound innovation; R\&D acquisition; R\&D cooperation; Sourcing

Mothe C., Université Savoie Mont Blanc, IREGE

Nguyen-Thi U., Luxembourg Institute of Socio-Economic (LISER)

Triguero A., Facultad de Ciencias Ecnomicas, Universidad de Castilla-La-Mancha 


\section{Introduction}

Environmental innovation (EI) has been defined in various ways, to include different types of innovation (i.e., technological or non-technological), depending on the researchers' objectives and questions. For example, Rennings (2000: 322) views EI as "measures of relevant actors (firms ...) which: (i) develop new ideas, behavior, products and processes, (ii) apply or introduce them, and; (iii) contribute to a reduction of environmental burdens or to ecologically specified sustainability targets." Kemp (2010: 2) defines EI as the "production, assimilation or exploitation of a product, production process, service or management or business method that is novel to the organization (developing or adopting it) and which results, throughout its life cycle, in a reduction of environmental risk, pollution and other negative impacts of resources use (including energy use) compared to relevant alternatives." This study focuses specifically on technological EI, which implies new or significantly modified processes, products, or services that reduce environmental harms or generate environmental benefits, whether those benefits accrue to final customers or the firm itself. (Beise and Rennings, 2005; De Marchi, 2012). That is, the definition we adopt "is based on the effect of the innovation activities independent of the initial intent and includes both incremental and radical improvements" (De Marchi, 2012: 615).

Prior empirical work (e.g., Cleff and Rennings, 1999; Rehfeld et al., 2007; De Marchi, 2012; Triguero et al., 2013; Fleith et al., 2014) emphasizes the decisive influence of technological capabilities on EI. Such studies are anchored in a traditional technology-push view, for which technological determinants define innovation (Horbach, 2008), including environmental innovation, which tends to be perceived as a specific type of technological innovation. General success factors include markets, laws, regulations, interfunctional collaboration, and innovation-oriented learning (Fleith et al., 2014). In addition, unique to environmental innovation, it often correlates with stringent environmental policies (Frondel et al., 2008) and regulatory/institutional frameworks (Horbach, 2008; Cainelli et al., 2011; Belin et al., 2011; Berrone et al., 2013).

A vast stream of literature also deals with the effects of external knowledge and open innovation strategies on technological innovation (e.g., Laursen and Salter, 2006; Leiponen and Helfat, 2010). Because innovation draws on various sources of ideas, information, and knowledge, firms might enhance their chances of success by accessing more knowledge sources, networks of collaboration, or information exchanges. Wider horizons for accessing 
external knowledge sources also might be associated with successful innovation (Leiponen and Helfat, 2010). Accordingly, our aim is to investigate the influence of three modes of openness-acquiring, sharing, and sourcing-on the adoption of EI. The influence of open search strategies on EI has received some research attention (e.g., Ketata et al., 2014; Ghisetti et al. 2015; Marzucchi and Montresor, 2017), yet we still know relatively little about the precise role of different open search strategies on the distinct types of EI (process and product).

In this sense, our study differs from previous research in three important ways. First, we consider the role of different modes of inbound open innovative flows for EI and try to determine which of these three modes should have the greatest relevance for the development of EI. Although Ghisetti et al. (2015) test the effects of knowledge source depth and breadth on firms' EI, they focus mainly on external information sources; Marzucchi and Montresor (2017) investigate the knowledge drivers of firm eco-innovations but emphasize a distinction between "Science, Technology and Innovation" and "Doing, Using and Interacting" modes.

Second, we consider the separate influences of these three modes of inbound open innovative strategies on environmental product versus process innovations (henceforth, ecoproduct and ecoprocess), thus extending Cleff and Rennings's (1999) insights. We develop hypotheses about the more or less important associations of the three inbound strategies with product and process EI, in an effort to explicate the relationship between various modes of inbound open innovation and two types of EI, as well as determine whether these strategies have similar or different effects.

Third, we analyze the role of the breadth of inbound modes for EI and control for the non-linear relationship between them and EI (Ghisetti et al., 2015). In this regard, our objectives align with studies that test the influence of external sourcing on general innovation (Laursen and Salter, 2006) and EI (Ketata et al., 2014; Ghisetti et al., 2015). However, whereas those studies define openness according to the scope or depth of external sources, we consider technology acquisition transactions, external collaboration, and the role of external knowledge inflows. We also add the potential moderating effect of absorptive capacity, measured as the firm's internal $R \& D$, because external sources are difficult to absorb if the firm lacks this capability. That is, a lack of absorptive capacity may impede the firm's production of EI.

In the next section, we accordingly review prior literature on EI determinants, with a specific focus on openness modes, before we outline, in Section 3, the data set, variables, and 
methods. We used data collected from manufacturing firms in the French Community Innovation Survey (CIS) for the period 2006-2008. Section 4 presents the estimation results. Finally, we conclude with some implications for theory and practice and suggestions for further research.

\section{Literature review and hypotheses}

The economic importance of environmental innovation is undisputed, particularly as a means to reduce the negative externalities of pollution and waste (e.g., De Marchi, 2012; Ghisetti et al., 2015). Growing literature focuses on innovation with environmental effects and its determinants, such as regulatory and institutional frameworks or supply- and demand-side factors (e.g., Cainelli et al., 2011, 2015; Horbach, 2008). To develop environmentally friendly products, firms must be able to innovate, and this ability is tightly linked to the knowledge pool available or accessible to the firm (e.g., Laursen and Salter, 2006; Leiponen and Helfat, 2010). Researchers thus note the advantages of combining internal investments with external resources (Cassiman and Veugelers, 2002), and many firms open their innovation processes to access and exploit external knowledge while leveraging their internal resources for core activities (Chesbrough, 2006). By increasing the openness of their innovation processes, firms complement their internal R\&D and make better use of external knowledge; that is, traditional R\&D activities get augmented by external technologies or information sources (e.g., Ketata et al., 2014; Ghisetti et al., 2015). Therefore, a crucial element of open innovation activities is firms' search for external knowledge (Köhler et al., 2012).

Technological EI and more traditional technological innovation are analogous but distinct. First, "the knowledge required for successful sustainable innovation is both more complex and more uncertain than for traditional innovation engagements" (Ketata et al., 2014: 69). The additional layers, its changing nature, and its dependence on various stakeholder groups (Hall and Vredenbvurg, 2003; Carrillo-Hermosilla et al., 2010) contribute to the greater complexity of EI. In turn, it requires different knowledge bases, competencies, and resources (Ghisetti et al, 2015; Cainelli et al, 2015; Marzucchi and Montresor, 2017). Because of its relative newness, EI even may demand knowledge and competences that are not among the firm's current core competences (Horbach et al., 2012; Rennings and Rammer, 2010). Firms that strive for EI thus go beyond their core competences.

Second, as a stylized fact, EI requires knowledge inputs from heterogeneous sources, possibly more than other types of innovation (Ghisetti et al., 2015; Horbach et al., 2013; 
Rennings and Rammer, 2010). Therefore, external knowledge is more idiosyncratic for EI than for traditional technological innovation. In this vein, EI exhibits a strong dependence on the breadth and depth of external sources, as well as on the existing regulatory framework and public financial support (Ketata et al., 2014).

Although prior EI literature acknowledges the role of supply- and demand-side factors and regulations, the influence of openness remains unclear in light of the conflicting findings of extant empirical studies. By focusing on the effects of three modes of openness on ecoproduct and ecoprocess innovations, we predict that openness goes through different modes- $R \& D$ acquisition, R\&D cooperation, and external information sources (e.g., suppliers, customers, competitors, R\&D institutes)—-to enable firms to develop knowledge-based capabilities and leverage their innovation capabilities and competences. ${ }^{1}$ Moreover, we consider external knowledge assimilation, as reflected in the concept of absorptive capacity (Cohen and Levinthal, 1990), which should help firms develop EI (Ketata et al., 2014; Ghisetti et al., 2015).

\subsection{Supply-side determinants: Search strategies for external knowledge}

Open innovation reflects "how firms make decisions about whether to develop innovations internally or partner with external actors" (Dahlander and Gann, 2010: 700). From this perspective, firms make two important decisions about their search strategies for external knowledge. First, they must decide whether to use external knowledge. More open innovation should enable them to leverage external research and complement internal $R \& D$, such that traditional R\&D activities get augmented with inbound sourcing of external technologies (Chesbrough, 2006). Boundary-spanning activities thus can speed up innovative processes and improve innovation performance (Laursen and Salter, 2006; Spithoven et al., 2013). Second, when firms search for external knowledge, they choose among different modes. Dahlander and Gann (2010) identify two main forms. Inbound innovation is a process of acquiring or sourcing, such that the firm discovers, acquires, and uses information or resources developed by external partners. Outbound innovation implies that firms communicate their internal resources or competences to the external environment by revealing, signaling, or commercializing their resources. To investigate the extent to which the use of external knowledge influences firms' ability to introduce EI, we focus on inbound

\footnotetext{
${ }^{1}$ Such openness may lead to appropriability concerns. This "paradox of openness" is effectively addressed by Laursen and Salter (2014).
} 
innovation, the most widely studied type (West et al., 2014), and we detail three modes: acquisition, sharing, and sourcing.

Inbound innovation acquisition. This strategy refers to the acquisition of valuable resources or expertise from the marketplace (Dahlander and Gann, 2010) through either embodied technology purchases or external R\&D. First, the purchase of advanced machinery facilitates access to embodied technology. Investments in embodied technical knowledge increase the physical and knowledge capital stock of firms, thus incentivizing technological change (Rouvinen, 2002). The use of new equipment implies the generation of new knowledge, as a result of "learning by-doing" and "learning-by-using" effects (Cabral and Leiblein, 2001), or it complements other external knowledge obtained from the same industry or technological field (Hervas et al., 2014). The acquisition of new equipment, as a form of embodied knowledge, thus should encourage mainly process innovations (Rouvinen, 2002). Using the Spanish manufacturing CIS, Marzucchi and Montresor (2017) accordingly find a positive, significant effect of embodied $R \& D$ on the adoption of environmentally efficient technologies, but not on other types of eco-innovations (e.g., products). In line with these arguments and results, we predict:

Hla: Inbound innovation acquisition through the purchase of new machinery is likely to be more associated with ecoprocess than with ecoproduct innovations.

Firms also can gain access to an external knowledge base through external R\&D subcontracting or acquiring technologies from external partners (licensing). These operations imply a monetary reward for externally purchased ideas but also may complement the firm's internal knowledge base, increasing the likelihood of exploration and exploitation success. Unlike patented license acquisitions, external $R \& D$ acquisition requires a mutual understanding between the focal firm and the seller of technology. External R\&D generally is beneficial only if it exhibits some complementarity with the focal firm's internal knowledge (Cassiman and Veugelers, 2006). However, empirical evidence of the influence of external R\&D on ecoproduct and ecoprocess innovation is inconclusive: Horbach et al. $(2012,2013)$ find a slightly negative influence, but only on process innovations with environmental benefits in areas such as energy, dangerous materials, and recycling. De Marchi (2012) and Marzucchi and Montresor (2017), using the Spanish CIS, do not find any significant influence of the acquisition of external knowledge, in the form of patents or licenses, on ecoinnovations (either process or product). According to Bönte and Dienes (2013), with data from 15,200 manufacturing firms across 14 European countries gathered in the fourth CIS 
wave, firms engaged in external $R \& D$ exhibit a lower probability of introducing energy and material efficiency process innovations.

Taking into account the costs of external $R \& D$ acquisition, a firm may be more willing to take this risk for product innovations than for process improvements, which tend to have smaller impacts. Due to the different characteristics of knowledge involved in product and process innovations, firms benefit less from complementing their internal knowledge with external R\&D for process innovations than for product innovations, in terms of knowledge creation. This theoretical assertion is corroborated by cross-sectional firm-level results that reveal significant complementarities between internal and external $R \& D$ for product but not for process innovations (Krzeminska and Eckert, 2016). In light of these considerations and previous empirical results, we predict:

HIb: Inbound innovation acquisition through external $R \& D$ is likely to be more associated with ecoproduct than with ecoprocess innovations.

Inbound innovation sharing. This type of openness implies that firms enhance their ability to introduce new or improved products or processes by building partnerships with other firms or non-commercial organizations. Firms that engage in collaboration gain access to complementary partners' knowledge or synergistic skills and capitalize on "incoming spillovers" (Kogut, 1988; Kogut and Zander, 1993; Cassiman and Veugelers, 2002), such that they can access technology that they could not acquire from the market (Hagedoorn, 1993), reduce any duplication of $R \& D$ efforts, mitigate the risks and costs associated with innovation projects (Sakakibara, 1997), and gain economies of scale or scope (Kogut, 1988). Research on the influence of R\&D collaboration on EI offers convergent results: The effect is positive (De Marchi, 2012). For example, European SMEs that collaborate with various actors increase market demand for their product EI (Triguero et al., 2013). Collaborative networks with universities and public institutions are also essential drivers of all types of EI (Cainelli et al., 2011; Triguero et al., 2013). Firms actively develop R\&D partnerships to benefit from the incoming spillovers (Kogut and Zander, 1993; Triguero et al., 2013).

However, inter-organizational cooperation may be more beneficial for ecoprocess than for ecoproduct innovation, perhaps due to the appropriability concerns that arise for product EI. Horbach et al. (2013) note a significant influence of R\&D cooperation, but only for EI with environmental benefits for the firms that are related to dangerous substances (i.e., process innovation). Marzucchi and Montresor (2017) also find a positive influence of 
cooperation on efficiency-related eco-innovations but not on the adoption of end-of-pipe solutions or new green products. That is, empirical evidence about the influence of R\&D cooperation on green product adoption is somewhat uncertain (Marzucchi and Montresor, 2017), but that pertaining to process EI seems to converge. Noting that firms' willingness to share knowledge about ecoprocess innovations (continuous, incremental) seems higher than their disposition to share ecoproduct innovations (discontinuous, radical) (Del Río et al., 2010; Triguero et al. 2013), we develop the following hypothesis:

H2: Inbound innovation sharing (cooperation) is likely to be more associated with ecoprocess than with ecoproduct innovations.

Inbound innovation sourcing. Innovation sourcing describes the extent to which firms can use external information sources for their own innovation activities (Dahlander and Gann, 2010). Sourcing is a non-pecuniary inbound innovation used by the firm to search for freely available external ideas or knowledge to apply to their own $R \& D$ projects.

Despite considerable research on open innovation, empirical studies of the relationship between information sourcing and EI remain relatively scarce. However, the systematic, complex, multipurpose nature of EI increases the need for an expanded internal knowledge base (Belin et al., 2011; De Marchi, 2012; Ghisetti et al., 2015). Using CIS 2006-2008 from 11 European countries, Ghisetti et al. (2015) reveal that knowledge sourcing (breadth and depth) is positively associated with EI introductions, though, they do not distinguish the influences of different sources of information. Ketata et al. (2014) obtain similar results with data from 1,124 German firms; they account for the firms' internal capabilities and absorptive capacity and confirm that the breadth and depth of innovation sources enhance successful sustainable innovations.

We consider different types of external sources of information, reflecting the specificities that mark cleaner technologies, relative to other alternative (or conventional) technologies. That is, the interests and needs of all the partners in this highly uncertain and complex context makes external knowledge sources particularly important (Ketata et al., 2014). Because EI is more high-tech, complex, and dependent on governmental policy interventions than most technological innovations, we dedicate particular attention to institutional sources. Moreover, the high level of uncertainty with respect to the impacts along the value chain (and environmental and social concerns) suggests that firms need to pay attention to market sources, reflecting the status of these markets as uncertain and unknown. 
Similar to prior empirical studies of the sources of innovation and collaborative networks, we distinguish external market from institutional sources (e.g., Amara and Landry, 2005). ${ }^{2}$

For market sources, we include suppliers, users, and competitors (Laursen and Salter, 2006), which offer "soft" openness-typically, knowledge sharing without entering into legally binding agreements. Market sources enable knowledge-based innovations derived from the linkages between the actors (suppliers, customers, competitors). As previous literature shows (e.g. Geffen and Rothenberg, 2000; Kammerer, 2009), such knowledge from suppliers and customers is relevant for eco-innovation. Market sources help firms collect and absorb information about the needs and demands of clients, as well as exploit information about the EI programs of their competitors.

When it comes to the effects of such sources on process versus production innovations, Marzucchi and Montresor (2017) find that knowledge from suppliers, customers, competitors, industry associations, trade fairs, and conferences (synthetic knowledge) is highly relevant for all types of eco-innovation but especially so for ecoprocess innovations related to material or energy reduction, relative to end-of-pipe technologies or the implementation of green products. This result seems somewhat counterintuitive, considering the effect of market competition on the returns from product and process innovations (Cohen and Klepper, 1996). Because product innovations are easier to imitate and appropriate, perhaps knowledge from external market sources is especially valuable when introducing new products in highly competitive conditions. In turn, the role of non-scientific knowledge sources (customers, suppliers, competitors) might be more critical for enhancing product than process innovation, because the former is more market driven than the latter. However, these non-scientific knowledge sources also could lead to rather incremental innovations. According to Jensen et al. (2007), tacit knowledge gained from a synthetic knowledge base provided by market sources frequently prompts learning-by-doing, using, and interacting (DUI) knowledge modes. Theoretically then, such market sources should be more beneficial for the introduction of product EI, and we hypothesize:

H3a: Inbound innovation sourcing from external market sources is likely to be more associated with ecoproduct than with ecoprocess innovations.

\footnotetext{
${ }^{2}$ We also add a third type of information sourcing (i.e., other sources) to our model but do not elaborate a specific hypothesis for this category, because it includes a vast set of diverse sources, such as patents, databases, trade literature, and fairs.
} 
Institutional sources of information facilitate knowledge-based innovations derived from science and related more directly to national innovation systems. Public research infrastructures enhance knowledge inflows and outflows among firms and institutions, generating an analytical knowledge base (Herstad et al., 2014). In terms of the relevance of knowledge from institutions such as universities, governments, and public research institutes, the development of more radical innovations (product) demands more analytical knowledge than does the development of more incremental innovations (process). Belin et al. (2011) accordingly find a significant positive influence of institutional sources (universities) on EI in France (see also Bönte and Dienes, 2013). Despite empirical evidence of a positive influence of knowledge from institutional sources on innovation, only Marzucchi and Montresor (2017) and Del Río et al. (2010) distinguish their effects for process versus product EI. Marzucchi and Montresor (2017) show that these sources influence environmentally efficient technologies, such as material or energy reduction processes, but not the introduction of environmental products. In contrast, Del Río et al. (2010) only find positive influences of knowledge from institutional sources on product EI. Thus, we posit:

H3b: Inbound innovation sourcing from institutional sources is likely to be more associated with ecoproduct than with ecoprocess innovations.

\subsection{Absorptive capacity as a moderator between inbound modes and EI}

Absorptive capacity (AC) fosters the recognition, assimilation, and application of external knowledge (Cohen and Levinthal, 1990). It "helps a firm to link external and internal technology sourcing, and thereby to benefit from ambidexterity in technology sourcing" (Rothaermel and Alexandre, 2009: 764), and it facilitates the assimilation of new technologies developed elsewhere. Essential for knowledge sharing and sourcing (Liao et al., 2007), AC has a pivotal function in terms of accessing knowledge from external partners (Koch and Strotmann, 2008). This capacity is a key link between knowledge sharing and innovation (Muller and Zenker, 2001). Using a productivity approach, Cassiman and Veugelers (2006) find improved innovation performance with a combination of internal and external R\&D; in particular, external $R \& D$ enhances internal $R \& D$ if firms' willingness to use external ideas helps them avoid the "not-invented-here" syndrome (Katz and Allen, 1982; Lichtenthaler and Ernst, 2006).

Various studies focus on the factors on which AC depends, such as internal R\&D, which increases the intelligibility of external knowledge related to EI by reducing the cognitive 
distance between the firm and external providers (Ghisetti et al., 2015). But AC also embodies a firm's ability to handle knowledge internally and constitutes a "second face" of $R \& D$ (Cohen and Levinthal, 1989). It enables the acquisition, assimilation, transformation, and exploitation of knowledge related to natural environmental protections through proactive environmental strategies. Moreover, AC combined with management support facilitates the adoption of successful environmental strategies and competitive advantages (Delmas et al., 2011; Lenox and King, 2004). Even though most research has focused on the combination of external and internal $R \& D$, we hypothesize that internal $R \& D$ is necessary for any types of external sources to be assimilated, which implies a moderating effect of $\mathrm{AC}$, measured through internal $\mathrm{R} \& \mathrm{D}$, on the links between inbound innovation and both types of EI:

H4: Absorptive capacity positively moderates the relationship between inbound modes and $E I$.

We elaborate a theoretical model in which firms expand their boundaries with open inbound strategies to increase their technological base for EI. In line with previous literature, we anticipate that the ability to assimilate and exploit external knowledge (acquired, shared with co-partners, or sourced from institutions or markets) builds on the firm's AC. From this perspective, external $R \& D$ and the acquisition of embodied technology (pecuniary form), R\&D collaboration (mixed in pecuniary terms), and sourcing of knowledge (non-pecuniary form) do not replace in-house innovation activities (intramural R\&D activities) but rather act as necessary actions to complement the firm's knowledge base, needed to implement ecoprocess and ecoproduct innovations.

\section{Data and methodology}

\subsection{Data}

Firm-level data were drawn from the French CIS for 2006-2008. This survey collects general information about firms (activity sector, group, number of employees, sales, geographic market), technological and non-technological innovations, perceptions of factors that may hamper innovative activities, and subjective evaluations of innovation outcomes. The survey also provides information about strategies pursued by the firm to search external knowledge and other variables related to the innovation process $(R \& D$, internal sources of 
knowledge information, cost reduction motives). We chose French manufacturing firms for two reasons. First, France has been a primary European adopter of eco-innovation in recent decades. According to the 2015 Eco-Innovation Scoreboard, France ranks seventh among the 28 EU member states in terms of tis eco-innovation. Second, France's strong tradition of environmental regulation and support schemes, targeting both public and private actors (Ecoinnovation Observatory, 2016), justifies a closer consideration of the influence of inbound modes of knowledge on environmental innovation. In this study, we consider all firms that operate in the manufacturing sector, such that the resulting sample of 4,705 observations helps ensure the robustness of our analysis.

\subsection{Dependent variables}

In line with Ziegler (2015), we distinguish two dichotomous variables to determine if the firm produced an EI during the focal period. Ecoproduct (ecoprocess) is a binary variable, equal to 1 if the firm introduces a new or significantly improved product (process) with environmental benefits, which may be generated during the production stage in which it produces goods or services (e.g., reduced material use per unit of output, recycled waste, water, materials) or in the after-sales stage during the product's or service's use by end users (e.g., reduced air, water, soil, or noise pollution; reduced energy use; improved recycling of product after use). It equals 0 otherwise. Appendixes 1 and 2 contain the variable definitions and descriptive statistics, showing that $33 \%$ of firms in our sample introduced new or significantly improved ecoproducts, and 34\% introduced ecoprocesses.

\subsection{Independent variables}

To investigate the relationship between openness and environmental innovation, we use external $R \& D$ acquisition, $R \& D$ cooperation, and different external sources of information as proxies for openness, classified according to three modes: inbound acquiring, inbound sharing, and inbound sourcing.

For inbound acquiring, we consider two binary variables: (1) acquisition of advanced machinery, software, or licensed patents and non-patent inventions or know-how to produce new or significantly improved products and processes and (2) external R\&D, which reflects whether firms' innovation activities during the period were performed by other firms or public or private research organizations and then purchased by the focal firm. The measure for inbound sharing, R\&D cooperation is a binary variable that indicates whether firms have 
cooperated in any of their innovation activities with other firms or institutions during 20062008. For inbound sourcing, we introduced the different sources of information. Market sources refer to suppliers, clients, competitors, or other firms in the sector, as well as consultants, commercial labs, or private R\&D institutes. Institutional sources are universities, other higher education institutions, governments, and public research institutes. Finally, the category of other sources of information include patents, databases, trade literature, or fairs. These variables are equal to 1 if that specific source inflow is crucial to firm innovation activities and 0 otherwise.

We find that $33 \%$ of firms acquired embodied knowledge, $20 \%$ used external R\&D, and nearly $29 \%$ undertook R\&D cooperation. Regarding sources of information, $25 \%$ relied on market sources, $9 \%$ used other sources, and only $2 \%$ benefited from institutional sources ${ }^{3}$ (see Appendix 2).

As a robustness check, we also introduced a new measure to assess the breadth of inbound modes. Similar to Laursen and Salter (2006), Leiponen and Helfat (2010), and Ghisetti et al. (2015), this variable reflects three inbound innovation types. That is, we sum the three variables, Sourcing, Sharing, and Acquiring, to obtain Breadth, which varies from 0 when the firm uses no inbound information to 3 when it adopts all three modes. ${ }^{4}$

Researchers have measured AC with various indicators. Cohen and Levinthal (1990) use $R \& D$ intensity, but internal $R \& D$ is a more general measure. The convenience of measuring diverse internal sources of knowledge justifies the inclusion of an alternative variable, to check the robustness of our results. We therefore use intramural R\&D as a proxy for AC (see Appendix 1).

In line with prior literature, we introduce a set of environmental regulation variables, including existing or expected environmental regulations, taxes on pollution, environmental financial regulations, voluntary codes, and agreements for environmental good practices within the sector (Existing regulations and Expected regulations). We also add the firm's objective for introducing EI: financial, such as benefiting from grants, subsidies, or other financial incentives; as a response to legislation; reduced labor costs; as a response to market demand; or due to control procedures for regularly identifying and reducing environmental

\footnotetext{
${ }^{3}$ Institutional sources are still an infrequent method, though this variable equals 1 if the use of institutional sources is crucial for firm's innovation activities and 0 otherwise. The restriction is thus very high.

${ }^{4}$ We also ran a model with the breadth of six search strategies (acquisition, external R\&D, R\&D cooperation, market sources, institutional sources, other sources) instead of three inbound modes (sourcing, sharing, acquiring). It produced similar results, which are available on request.
} 
impacts, such as environmental audits, environmental performance goals, or ISO 14001 certifications (Control procedures). To account for market-pull determinants, we introduce the variable Market demand, equal to 1 if the firm introduced an EI in response to current and expected market demand from customers for environmental products or services, and 0 otherwise. The Market geography variable uses a four-point Likert response scale, with $1=$ local market, 2 = national, 3 = European, and $4=$ global market. The correlations across these variables are available in Appendix 3.

Finally, we include traditional control variables that may influence firms' EI capabilities. Firm size is the natural logarithm of the number of employees. Group belonging equals 1 if the firm belongs to a group and 0 otherwise. Firms that are members of a group tend to have more incentives for innovation activities, because of their easier access to financing (Love and Roper, 2001) and ability to apply the innovation strategy adopted by their headquarters. Four subsectors of activities reflect a two-digit NACE classification of manufacturing industries based on R\&D intensity (OECD, 2011): (1) high-tech, (2) medium high-tech, (3) medium low-tech, and (4) low-tech (reference category).

\section{Results and discussion}

We apply a bivariate Probit model, because the ecoprocess and ecoproduct variables are not exclusive. ${ }^{5}$ Table 1 contains the results of this bivariate Probit model for the likelihood of introducing EI. The results regarding the effects of openness on EI are significant, though we also find some differences across the influences of the various modes on ecoproduct and ecoprocess innovations.

Regarding inbound acquisition, we find a significant, strongly positive association of the acquisition of embodied technology with ecoproducts and ecoprocesses, but the latter link is stronger, in line with H1a. External R\&D similarly has significant influences on all types of EI, but it is stronger for ecoproducts than for ecoprocesses, in support of H1b. Inbound sharing (R\&D cooperation) is more positively associated with ecoprocesses at the firm level than with ecoproducts, in support of H2. Laursen and Salter (2014) explain that this type of non-pecuniary inbound open innovation is strongly influenced by a firm's pecuniary logic, as manifested by its capability to appropriate innovative returns.

\footnotetext{
${ }^{5}$ Reverse causality may be a concern. Any eco-innovation shock might induce changes in the firm's openness that are not directly due to changes in the firm's inbound strategies per se. Unfortunately, we cannot control for this possibility, because we lack instruments to do so in our data.
} 
The results for inbound sourcing vary with the type of information source. Market sources of information are positively and significantly associated with firms' involvement in ecoproduct and ecoprocess innovation, more so with products than with processes, in support of $\mathrm{H} 3 \mathrm{a}$, but only when we exclude a moderating role of intramural R\&D. However, the intensive use of institutional sources has no significant effect on the likelihood of ecoproduct or ecoprocess innovation, so we must reject H3b. Firms use collaborations with universities to explore new knowledge that is distant from their market, not to achieve new products and processes directly (Feller et al., 2002). Successful collaboration with universities demands prior ties, certain technological similarities, and geographic closeness (Petruzzelli, 2011), which may be more difficult for EI than for more traditional technological innovations, because of its newness. With regard to the other sources (e.g., patents, databases, trade literature, fairs), Table 1 indicates a slightly positive effect on ecoproducts, but only in the model that does not include absorptive capacity.

To test for the moderation of $\mathrm{AC}$, we consider the direct influence of intramural R\&D and its indirect influence for each mode of openness (Table 1), by introducing interaction terms between the inbound modes and intramural $\mathrm{R} \& \mathrm{D}^{6}$. The results show that all interaction terms are significant and negative. These counterintuitive results differ from those of recent empirical studies that indicate firms actively develop $R \& D$ partnerships to benefit from incoming spillovers (Kogut and Zander, 1993; Triguero et al., 2013). But the likelihood of EI decreases, with levels of significance that vary with the type of inbound sourcing, for firms that invest in both internal R\&D and external open innovation modes. We therefore reject H4.

\section{Insert Table 1 here}

As a robustness check, we test our hypotheses using a measure of the breadth of inbound modes for external knowledge, instead of individual modes of inbound innovation (Table 2). With this new specification, we can measure the search intensity and its nonlinear effects on ecoproducts and ecoprocesses. The results indicate that the Breadth of inbound modes has a positive, significant impact on EI in all models, which reinforces our previous findings (Table 1) and confirms the general hypothesis that openness drives EI. Furthermore, the parameter for Breadth ${ }^{2}$ is negative and strongly significant in all models, indicating decreasing returns on information sources when firms use too many search strategies. This

6 There are other possible moderating factors of the impact of the inbound modes on eco-innovations that enhance the absorption of external knowledge. Some studies (e.g. Franco et al., 2014) show that integration mechanisms related to the firm's human capital, such as the presence of a skilled workforce, positively moderate the influence of absorptive capacity on innovative performance. We thank a referee for this insight. 
result implies a curvilinear, inverted U-shaped relationship between the breadth of openness and EI. It appears that though intensive search strategies for external knowledge enhance the probability of EI, deepening this search beyond a certain level may be adverse. Perhaps the implementation and use of inbound information sourcing has some potential disadvantages, related to the difficulty of choosing and combining too many alternatives and aligning them with existing knowledge (Petruzzelli, 2011). Overly deep search strategies thus could have negative effects on firms' profitability and ability to introduce EI. Despite the positive effects of deep search strategies, exaggerating search beyond a certain level may create problems for allocating human and financial resources, such as developing and managing internal knowledge or searching for and assimilating external information. Such allocation challenges in turn might create a conflict-laden, adverse environment that hampers EI.

\section{Insert Table 2 here}

For the other explanatory variables, we find that reducing labor costs can help explain EI (Kesidou and Demirel, 2012; Horbach et al., 2012, 2013), especially ecoprocesses; the coefficient for ecoproducts is negative, probably due to appropriability concerns. Among the demand factors, the geographic market variable is positively and significantly associated with EI as a clean technology (firm level); the coefficient of ecoproduct innovation as end-of-pipe technologies (market level) instead is insignificant. As expected, we find positive, significant coefficients of market demand in all models (Horbach, 2008; Triguero et al., 2013).

Environmental policy factors also have important roles, as motivators that trigger both types of environmental innovation, though some differences arise depending on the nature of the regulation and the environmental policy instrument. In this regard, existing regulations enhance ecoproduct and ecoprocess innovations, encouraging the adaptation of environmental technologies and the alleviation of the double externality problem. The stringency of regulations probably influences the direction, rate, and radicalness of eco-innovations (Del Río et al., 2010). Although the influences of existing regulations are stronger for ecoprocess than for ecoproduct innovations, our results suggest that they are equally effective for both types, in contrast with previous studies that offer the contrary findings that existing regulations only affect ecoproduct innovations (Triguero et al., 2013) or else are crucial mainly for ecoprocess innovations (Cleff and Rennings, 2000). Expected regulations only increase the likelihood of adopting ecoproduct, not ecoprocess, innovations, a result that corroborates evidence provided by Horbach et al. (2012) regarding the positive influence of expected future regulations on environmental product innovations. Even with the greater 
significance for explaining ecoprocess innovations, we find positive coefficients for the influence of voluntary codes on both types of eco-innovation. That is, the adoption of voluntary agreements by firms probably makes it easier for them to face expected changes in regulations in the long term, based on the existing regulatory framework.

Regarding control procedures, or the existence of firm procedures to identify and reduce environmental impacts (e.g., audits, ISO 14001), substantial literature indicates positive influences on ecoproduct and ecoprocess innovations. Similar to these studies, we confirm these positive influences. However, we find no significant evidence for a role of subsidies or other public financial incentives (public funding), in contrast with Horbach's (2008) assertion of an important role of subsidies for motivating firms to introduce EI, but in line with some other studies (Belin et al., 2011; Triguero et al., 2013; Cuerva et al., 2014). Considering these heterogeneous consequences of different environmental policy instruments, green taxes established to reflect the abatement costs across firms and sectors seemingly could enhance efficiency and social welfare better than regulations, control procedures, and voluntary codes (Baumol and Oates, 1988). Mazzanti and Rizzo (2017) suggest that marketand regulation-driven environmental policy instruments should be combined with other measures, such as renewable quotas or organizational, behavioral, educational, and societal innovations, to promote eco-innovation. Despite the difficulty associated with designing an effective policy, tailored to specific sectors, our findings indicate that "ecological tax reforms" are needed to achieve a low carbon economy and accomplish international climate targets (Borghesi et al., 2015). We summarize all these results in Table 3.

\section{Insert Table 3 here}

\section{Conclusions}

This research analyzes the relevance of search strategies for external knowledge as they relate to environmental innovation. We explore the role of different modes of openness for EI, considering the influences of acquisition and external R\&D (inbound innovation acquiring), R\&D cooperation (inbound innovation sharing), and external information sources (inbound innovation sourcing), to explain environmentally friendly product and process innovations. To do so, we offer a bivariate Probit model, together with sensitivity and robustness checks, using data from the French CIS 2008. Our results provide novel evidence about the relationship between inbound open innovation strategies and EI. We find different effects of the diverse search strategies on the implementation of ecoproduct and ecoprocess 
innovations. Inbound acquiring (embodied technology or external $R \& D$ ) has a positive influence on ecoproducts and ecoprocesses. We find similar results for R\&D cooperation, confirming the essential role of formal cooperation agreements for both types of EI. Regarding information sources, market sources of information are positively and significantly associated with all types of EI; institutional sources do not exert any influence on EI. Overall, we find that most open search strategies contribute either to both types of EI or to neither. In line with our predictions, the acquisition of embodied technology and formal cooperation agreements are more important for ecoprocess than for ecoproduct innovations, whereas external knowledge from market sources (customers, suppliers, competitors) is more relevant for ecoproducts than for ecoprocesses. Different knowledge bases, appropriability mechanisms, and imitation processes related to each type of EI help explain these results. Furthermore, the results are in line with prior evidence that suggests there are no substantial differences in the drivers of product versus process innovations. Thus, firms adopt both types of EI to improve their competitive advantage, because one type of innovation often requires the other. As a managerial recommendation, our findings suggest a mixed ecoproductecoprocess strategy for firms that hope to benefit from an open approach.

Firms' absorptive capacity, captured as internal R\&D, negatively moderates the effect of search strategies for external knowledge on EI. This finding implies that a substitutive effect among internal R\&D and open search strategies could exist. Such strategies act as complements of AC up to a certain point, but then as substitutes thereafter, and this substitution effect likely is greater for firms with more R\&D capacity (Berchicci, 2013). Another tentative argument, similar to Ghisetti et al.'s (2015), suggests that interactions with external knowledge sources increase the chance of mismatches between external and internal $\mathrm{R} \& \mathrm{D}$ programs and generate problems related to the dispersion of decision makers' attention or resources. Finally, we consider the breadth of open search strategies and find what appears to be a curvilinear relationship between the breadth of search strategies and EI. Although intensive search strategies for external knowledge enhance the probability of EI, deepening this search beyond a certain level may be adverse for EI.

We seek to extend existing literature on open innovation and environmental innovation to analyze the influence of different inbound modes in the emergence of EI. External search strategies are more relevant for EI than for general innovation, and this type of innovation depends on the strategic interaction between internal and external knowledge, so the choice of appropriate combinations of openness is critical. To access a wide array of 
ideas and knowledge to enhance innovation with environmental benefits, companies should acquire outside embodied technology and licenses, subcontract their green $\mathrm{R} \& \mathrm{D}$, cooperate to access partners' knowledge, or rely on non-pecuniary external sources of innovation.

The implications for theory include the need for researchers to investigate more carefully how open search strategies might foster EI. They may be more crucial for EI than for other types of innovation (De Marchi, 2012), considering the macroeconomic consequences of such innovations on sustainable development. Empirical literature on the role of openness for firms' innovative performance focuses almost exclusively on traditional (or dirty) technological innovation. We contribute to literature on open innovation and EI by considering the relationships of various types of inbound open innovation inflows with product and process EI. Incorporating different forms of openness enables us to highlight their differentiated impacts on EI and the distinct moderating effects of firms' AC. For example, AC negatively moderates the influence of acquiring embodied technology and cooperation on the two types of EI, of external R\&D on product EI, and of market sources on process EI.

Our work is not exempt from limitations though. First, our data set comes from one country and survey, namely, France's CIS. Thus, the findings are generalizable only to other European countries that demonstrate similar patterns of eco-innovation and similar institutional frameworks. Second, we concentrate on manufacturing firms; service firms might also be of interest, considering their prominence in modern economies. Other independent variables related to openness might be added, such as belonging to a cluster, which is a primary channel for diffusing information across firms and gathering knowledge-based social capital to enhance EI. To inform public policy makers, research should compare the search strategies for EI against those for non-environmental innovations, to determine if EI requires more or different types of openness modes. Finally, assessing various complementarities among sources of information and across innovation types could be interesting; firms rarely choose to concentrate on one source or innovation type but instead prefer to combine them (Dahlander and Gann, 2010).

Notwithstanding these caveats, the evidence we present highlights implications for practice management related to the complex combination of internal and external knowledge required to enhance EI activities. All types of EI correlate generally positively with external modes of openness (acquisition, R\&D cooperation, sourcing); striking a balance between search strategies for external knowledge and intramural R\&D might be necessary in certain cases. In this regard, managers must consider the need to balance internal and external 
knowledge that enhances environmental performance. Because the search strategy for external knowledge and the level of intramural $\mathrm{R} \& \mathrm{D}$ is mainly determined by managers, an optimum level of ambidexterity might allow firms to configure and leverage their internal and external knowledge resources, in terms of the influence of technology sourcing strategies on environmental performance, moderated by absorptive capacity (Rothaermel and Alexandre, 2009). The influence of market sources of information on all types of environmental innovation also offers new evidence regarding the incorporation of ecological considerations into product design processes. Collaborative efforts and joint developments of green technologies in an open innovation framework can enhance the relationship between environmental collaboration in the supply chain and manufacturing performance, either upstream toward suppliers or downstream toward customers (Vachon and Klassen, 2008).

Finally, the implications for public policy, in terms of the macroeconomic consequences for sustainable development, need to be assessed. Our findings suggest that policy makers can promote EI by supporting different search strategies for external knowledge that complement internal knowledge bases. A country might promote EI by enhancing the openness of its national innovation system and use firm subsidies to encourage collaborations with universities or technology centers. We know little about the influence of collaborations with universities, so further research could offer great potential for determining effective policy measures that can support university-industry collaborations in EI. A challenge to the "open eco-innovation mode," as detailed in the 2011 Eco-Innovation Action Plan by the European Commission, could be the need to move beyond green innovative processes, products, and services to reinforce the objectives pursued during the transition to a resource-efficient, low-carbon economy. Fostering inbound and outbound innovation processes beyond the EU also could enable the development and implementation of policy programs to stimulate or enforce more sustainable innovations, to transfer, translate, and transform knowledge (Carlile, 2004) across firm, geographical, sectorial, and institutional boundaries.

\section{References}

Amara, N. and R. Landry. 2005. "Sources of information as determinants of novelty of innovation in manufacturing firms: evidence from 1999 statistics Canada innovation survey." Technovation 25(3): 245-259. 
Baumol, W.J. and W.E. Oates. 1988. The theory of environmental policy. Cambridge University Press.

Beise M. and K. Rennings. 2005. "Lead Markets and Regulation : a Framework for Analyzing the International Diffusion of Environmental Innovations." Ecological Economics 52(1): 517.

Belin, J., Horbach, J. and V. Oltra. 2011. "Determinants and specificities of eco-innovations: an econometric analysis for the French and German industry based on the Community Innovation Survey." GRETA 2011-17.

Berchicci, L. 2013. "Towards an open R\&D system: internal R\&D investment, external knowledge acquisition and innovative performance." Research Policy 42(1): 117-127.

Berrone, P., Fosfuri, A., Gelabert, L. and L.R. Gomez-Mejia. 2013. "Necessity as the mother of 'green' inventions: Institutional pressures and environmental innovations." Strategic Management Journal 34(8): 891-909.

Bönte, W. and C. Dienes. 2013. "Environmental innovations and strategies for the development of new production technologies: empirical evidence from Europe." Business Strategy and Environment 22(8): 501-516.

Borghesi, S., Crespi, F., D’Amato, A., Mazzanti, M and F. Silvestri. 2015. "Carbon abatement, sector heterogeneity and policy responses: evidence on induced eco innovations in the EU." Environmental Science \& Policy 54: 377-388.

Cabral, R., and M. J. Leiblein. 2001. "Adoption of a process innovation with Learning-by-Doing: Evidence from the semiconductor industry.” The Journal of Industrial Economics 49(3): 269-280.

Cainelli, G., De Marchi, V., and R. Grandinetti. 2015. "Does the development of environmental innovation require different resources? Evidence from Spanish manufacturing firms. ” Journal of Cleaner Production 94: 211-220.

Cainelli, G., Mazzanti, M. and R. Zoboli. 2011. "Environmental innovations, complementarity and local/global cooperation: evidence from North-East Italian industry." International Journal of Technology, Policy and Management 11(3): 328-368.

Carlile, P. R. 2004. “Transferring, translating, and transforming: An integrative framework for managing knowledge across boundaries." Organization Science 15(5): 555-568.

Carrillo-Hermosilla, J., del Río, P. and T. Könnölä. 2010. "Diversity of eco-innovations: Reflections from selected case studies." Journal of Cleaner Production 18(10), 1073-1083. 
Cassiman, B. and R. Veugelers. 2002. "R\&D co-operation and spillovers: some empirical evidence from Belgium.” American Economic Review 92(4): 1169-1185.

Cassiman, B. and R. Veugelers. 2006. "In search of complementarity in innovation strategy: Internal R\&D and external knowledge acquisition.” Management Science 52(1): 62-82.

Chesbrough, H.W. 2006. "Open Business Models: How to Thrive in the New Innovation Landscape". Boston, MA: Harvard Business School Press.

Cleff T. and K. Rennings. 1999. "Determinants of environmental product and process innovation." Environmental Policy and Governance 9(5): 191-201.

Cohen, W. M. and Klepper, S. 1996. "Firm size and the nature of innovation within industries: the case of process and product R\&D." The review of Economics and Statistics, 78: $232-243$.

Cohen, W.M. and D.A Levinthal. 1989. "Innovation and learning: the two faces of R\&D." The Economic Journal 99(397): 569-596.

Cohen W.M. and Levinthal D.A. 1990. "Absorptive capacity: a new perspective on learning and innovation." Administrative Science Quarterly 35(1): 128-152.

Cuerva, M. C., Triguero, A. and D. Córcoles. 2014. "Drivers of green and non-green innovation: empirical evidence in Low-Tech SMEs." Journal of Cleaner Production 68: 104-113.

Dahlander, L. and D.M. Gann. 2010. "How open is innovation?" Research Policy 39(6): 699709.

Delmas, M., Hoffman, V. and M. Kuss 2011. "Under the tip of the iceberg: absorptive capacity, environmental strategy and competitive advantage." Business \& Society 50(1): $116-154$

Del Río, P., Carrillo-Hermosilla, J. and T. Könnölä. 2010. "Policy strategies to promote eco-innovation.” Journal of Industrial Ecology, 14(4): 541-557.

De Marchi, V. 2012. "Environmental innovation and R\&D cooperation: Empirical evidence from Spanish manufacturing firms." Research Policy 41(3): 614-623.

Eco-innovation observatory. 2016. Eco-innovation in France. Country profile 2014-2015 (https://ec.europa.eu/environment/ecoap/sites/ecoap_stayconnected/files/field/fieldcountry-files/france_eco-innovation_2015.pdf).

Feller, I., Ailes, C. and D. Roessner. 2002. "Impacts of research universities on technological innovation in industry: Evidence from engineering research centres." Research Policy, 26(3): 317-330. 
Fleith de Medeiros, J., Duarte Ribeiro, J.L. and M. Nogueira Cortimiglia. 2014. "Success factors for environmentally sustainable product innovation: a systematic literature review." Journal of Cleaner Production 65: 76-86.

Franco, C., Marzucchi, A., and S. Montresor. 2014. "Absorptive capacity, proximity in cooperation and integration mechanisms. Empirical evidence from CIS data”. Industry and Innovation, 21(4): 332-357.

Frondel, M., Horbach, J. and K. Rennings 2008. "What triggers environmental management and innovation? Empirical evidence for Germany." Ecological Economics 66: 153-160.

Geffen, C. and S. Rothenberg. 2000. "Suppliers and environmental innovation - the automotive paint process.” International Journal of Operations \& Production Management 20(20): 166-186.

Ghisetti, C., Marzucchi, A. and S. Montresor. 2015. "The open eco-innovation mode. An empirical investigation of eleven European countries." Research Policy 44(5): 1080-1093.

Hagedoorn, J. 1993. "Understanding the rationale of strategic technology partnering: New organizational modes of cooperation and sectoral differences." Strategic Management Journal 14(5): 371-385.

Hall, J. and H. Vredenburg. 2003. "The challenges of innovating for sustainable development" MIT Sloan Management Review 45(1): 61-68.

Herstad, S.J., Wiig Aslesen, H. and B. Ebersberger. 2014. “On industrial knowledge bases, commercial opportunities and global innovation network linkages." Research Policy 43: $495-504$.

Hervas-Oliver, J. L., Sempere-Ripoll, F. and C. Boronat-Moll. 2014. "Process innovation strategy in SMEs, organizational innovation and performance: a misleading debate?." Small Business Economics, 43(4): 873-886.

Horbach, J. 2008. "Determinants of environmental innovation-new evidence from German panel data sources." Research Policy 37(1): 163-173.

Horbach, J., Oltra, V. and J. Belin. 2013. "Determinants and specificities of eco-innovations compared to other innovations - an econometric analysis for the French and German industry based on the community innovation survey." Industry \& Innovation 20(6): 523543.

Horbach, J., Rammer, C. and K. Rennings. 2012. "Determinants of eco-innovations by type of environmental impact-The role of regulatory push/pull, technology push and market pull." Ecological Economics 78: 112-122. 
Jensen, M.B., Johnson, B., Lorenz, E. and B.A. Lundvall. 2007. "Forms of knowledge and modes of innovation." Research Policy 36 (5): 680-693.

Kammerer, D. 2009. "The effects of customer benefit and regulation on environmental product innovation. Empirical evidence from appliance manufacturers in Germany." Ecological Economics 68: 2285-2295.

Katz, R. and T.J. Allen. 1982. "Investigating the not invented here (NIH) syndrome: a look at the performance, tenure, and communication patterns of $50 \mathrm{R} \& \mathrm{D}$ project groups." $R \& D$ Management 12: 7-20.

Kemp, R. 2010. "Eco-innovation: Definition, Measurement and Open Research Issues." Economia politica 3: 397-420

Kesidou, E. and P. Demirel. 2012. "On the drivers of eco-innovations: Empirical evidence from the UK." Research Policy 41(5): 862-870.

Ketata, I., Sofka, W. and C. Grimpe. 2014. "The role of internal capabilities and firms' environment for sustainable innovation: evidence for Germany." $R \& D$ Management 45(1): $61-75$.

Koch, A. and H. Strotmann. 2008. "Absorptive capacity and innovation in the knowledge intensive business service sector." Economics of Innovation and New Technology 17(6): 511-531.

Köhler, C., Sofka, W. and Grimpe, C. 2012. "Selective search, sectoral patterns, and the impact on product innovation performance." Research Policy 41(8): 1344-1356.

Kogut, B. 1988. "Joint Ventures: Theoretical and Empirical Perspectives." Strategic Management Journal 9: 319-332.

Kogut, B. and U. Zander. 1993. "Knowledge of the Firm and the Evolutionary Theory of the Multinational Corporation.” Journal of International Business Studies 24(4): 625-645.

Krzeminska, A. and C. Eckert. 2016. Complementarity of internal and external R\&D: is there a difference between product versus process innovations? R\&D Management 46: 931-944.

Laursen, K. and A. Salter. 2006. "Open for innovation: the role of openness in explaining innovation performance among U.K. manufacturing firms.” Strategic Management Journal 27(2): 131-150.

Laursen, K. and A. Salter. 2014. "The paradox of openness: Appropriability, external search and collaboration." Research Policy 43(5): 867-878.

Leiponen, A. and C.E. Helfat. 2010. "Innovation objectives, knowledge sources, and the benefits of breadth.” Strategic Management Journal 31(2): 224-236. 
Lenox, M. and A. King. 2004. "Prospects for developing absorptive capacity through internal information provision." Strategic Management Journal 25(4): 331-345.

Liao, S.H., Fei, W.C. and C.C. Chen. 2007. "Knowledge sharing, absorptive capacity, and innovation capability: an empirical study of Taiwan's knowledge-intensive industries." Journal of Information Science 33(3): 340-359.

Lichtenthaler, U. and H. Ernst. 2006. "Attitudes to externally organizing knowledge management tasks: a review, reconsideration and extension of the NIH syndrome." $R \& D$ Management 36: 367-367.

Love, J.H. and S. Roper. 2001. "Location and network effects on innovation success: Evidence for UK, German and Irish manufacturing plants.” Research Policy 30(4): 643661.

Marzucchi, A. and Montresor, S. 2017. Forms of knowledge and eco-innovation modes: Evidence from Spanish manufacturing firms. Ecological Economics 131: 208-221.

Mazzanti, M. and U. Rizzo, U. 2017. "Diversely moving towards a green economy: Technoorganisational decarbonisation trajectories and environmental policy in EU sectors." Technological Forecasting and Social Change, 115: 111-116.

Muller, E. and A. Zenker. 2001. "Business services as actors of knowledge transformation: The role of KIBS in regional and national innovation systems." Research Policy 30(9): $1501-1516$.

OECD. 2011. ISIC Rev.3 Technology intensity definition classification of manufacturing industries into categories based on R\&D intensities.

Petruzzelli, A. M. 2011. "The impact of technological relatedness, prior ties, and geographical distance on university-industry collaborations: a joint-patent analysis." Technovation 31(7): 309-319.

Rehfeld K., Rennings K. and A. Ziegler. 2007. "Integrated product policy and environmental product innovations: an empirical analysis." Ecological Economics 61: 91-100.

Rennings, K. 2000. "Redefining innovation - eco-innovation and the contribution from ecological economics.” Ecological Economics 32: 319-332.

Rennings, K. and C. Rammer. 2010. “The Impact of Regulation-Driven Environmental Innovation on Innovation Success and Firm Performance." ZEW - Centre for European Economic Research Discussion Paper No. 10-065.

Rothaermel, F.T. and M.T Alexandre. 2009. "Ambidexterity in technology sourcing: the moderating role of absorptive capacity." Organization Science 20(4): 759-780. 
Rouvinen, P. 2002. "Characteristics of product and process innovators: Some evidence from the finish innovation survey." Applied Economics Letters 9: 575-580.

Sakakibara, M. 1997. "Heterogeneity of firm capabilities and co-operative research and development: an empirical examination of motives.” Strategic Management Journal 18(6): 143-16.

Spithoven, A., Vanhaverbeke, W. and N. Roijakkers. 2013. Open innovation practices in SMEs and large enterprises." Small Business Economics 41(3): 537-562.

Triguero, A., Moreno-Mondéjar, L. and M.A. Davia. 2013. "Drivers of different types of ecoinnovation in European SMEs.” Ecological Economics 92: 25-33.

Vachon, S. and R.D. Klassen. 2008. "Environmental management and manufacturing performance: the role of collaboration in the supply chain." International Journal of Production Economics 111(2): 299-315.

West, J., Salter, A., Vanhaverbeke, W. and H. Chesbrough. 2014. "Open innovation: The next decade." Research Policy 43(5): 805-811.

Ziegler, A. 2015. "Disentangling technological innovations: a micro-econometric analysis of their determinants." Journal of Environmental Planning and Management 58(2): 315-335. 


\section{Appendix 1. Variable definitions}

\begin{tabular}{ll}
\hline \hline Variables & \\
\hline Dependent variables & \multicolumn{1}{c}{ Description } \\
Ecoproduct & $\begin{array}{l}\text { Equal to } 1 \text { if the firm has introduced a product innovation (new or significantly improved goods and } \\
\text { services) that generates environmental benefits during the production stage (reduced material use } \\
\text { per unit of output; recycled waste, water, or materials) within the firm or/and in the after-sales stage } \\
\text { (reduced air, water, soil or noise pollution; reduced energy use; improved recycling of product after } \\
\text { use); and } 0 \text { otherwise }\end{array}$ \\
& $\begin{array}{l}\text { Equal to } 1 \text { if the firm has introduced a process innovation (new or significantly improved } \\
\text { production or distribution processes) that generates environmental benefits during either the } \\
\text { production stage (reduced material use per unit of output; recycled waste, water, or materials) } \\
\text { within the firm or the after-sales stage (reduced air, water, soil or noise pollution; reduced energy } \\
\text { use; improved recycling of product after use); and 0 otherwise }\end{array}$
\end{tabular}

Openness

Breadth

Varies from 0 if the firm uses any inbound mode to 3 if it uses all three inbound modes simultaneously.

Acquisition

Equal to 1 if the firm has acquired advanced machinery, equipment, and computer hardware or software to produce new or significantly improved products and processes, and 0 otherwise

External R\&D

R\&D Cooperation

Equal to 1 if the firm's R\&D activities are performed by other firms or public or private research organizations and purchased by the firm, and 0 otherwise

Equal to 1 if the firm undertakes R\&D cooperation for innovation activities with other firms or institutions during 2006-2008, and 0 otherwise

Market sources

Equal to 1 if competitors, suppliers, customers, consultants, and private R\&D institutes as sources of information are "crucial" for the firm's innovation process, and 0 otherwise

Institutional sources

Equal to 1 if universities, other higher education institutions, government, or public research institutes as sources of information are "crucial" for the firm's innovation process, and 0 otherwise

Other sources

Equal to 1 if conferences, scientific journals, professional associations, or technical standards as sources of information are "crucial" for the firm's innovation process, and 0 otherwise

\section{Other supply factors}

Intramural R\&D

Equal to 1 if the firm undertakes internal R\&D activities to increase its stock of knowledge, and 0 otherwise

Cost reduction

Equal to 1 if the firm has introduced an environmental innovation to reduce labor costs, and 0 otherwise

Internal sources

Equal to 1 if departments within the firm or enterprises within the same group as sources of information are "crucial" for the firm's innovation process, and 0 otherwise

Environmental policy factors

Existing regulations

Equal to 1 if the firm has introduced an environmental innovation in response to existing environmental regulations or taxes on pollution, and 0 otherwise

Expected regulations

Equal to 1 if the firm has introduced an environmental innovation in response to environmental regulations or taxes that the firm expects to be introduced in the future, and 0 otherwise

Environmental codes

Equal to 1 if the firm has introduced an environmental innovation in response to voluntary codes or agreements for environmental good practices within the sector, and 0 otherwise

Control procedures

Public funding

Equal to 1 if the firm has procedures in place to regularly identify and reduce environmental impacts, such as environmental audits, environmental performance goals, or ISO 14001 certification, and 0 otherwise

Equal to 1 if the firm has introduced an environmental innovation in response to the availability of 
government grants, subsidies, or other financial incentives, and 0 otherwise

Demand factors

Market demand

Market geography

Control variables

Belonging to group

Size

High technology

Medium high technology

Medium low technology

Low technology
Equal to 1 if the firm has introduced an environmental innovation in response to current and expected market demand from customers for environmental innovations, and 0 otherwise

Four-point Likert response scale: $1=$ local, $2=$ national, $3=$ European, and $4=$ global

Equal to 1 if part of a group; and 0 otherwise

Logarithm of the number of employees

High-tech manufacturing

Medium high-tech manufacturing

Medium low-tech manufacturing

Low-tech manufacturing (reference) 
Appendix 2. Descriptive statistics

\begin{tabular}{|c|c|c|c|c|c|}
\hline Variable & Obs. & Mean & Std. Dev. & Min & $\operatorname{Max}$ \\
\hline Ecoproduct & 4705 & 0.33 & 0.47 & 0 & 1 \\
\hline Ecoprocess & 4705 & 0.34 & 0.48 & 0 & 1 \\
\hline Breadth & 4705 & 1.00 & 1.14 & 0 & 3 \\
\hline $\mathrm{R} \& \mathrm{D}$ cooperation & 4705 & 0.30 & 0.45 & 0 & 1 \\
\hline Acquisition & 4705 & 0.33 & 0.47 & 0 & 1 \\
\hline External R\&D & 4705 & 0.21 & 0.40 & 0 & 1 \\
\hline Market sources & 4705 & 0.25 & 0.46 & 0 & 1 \\
\hline Institutional sources & 4705 & 0.03 & 0.16 & 0 & 1 \\
\hline Other sources & 4705 & 0.09 & 0.29 & 0 & 1 \\
\hline Existing regulations & 4705 & 0.25 & 0.43 & 0 & 1 \\
\hline Expected regulations & 4705 & 0.16 & 0.37 & 0 & 1 \\
\hline Environmental codes & 4705 & 0.16 & 0.40 & 0 & 4 \\
\hline Control procedures & 4705 & 0.31 & 0.46 & 0 & 1 \\
\hline Public funding & 4705 & 0.06 & 0.24 & 0 & 1 \\
\hline Cost reduction & 4705 & 0.26 & 0.43 & 0 & 1 \\
\hline Internal sources & 4705 & 0.36 & 0.48 & 0 & 1 \\
\hline Market demand & 4705 & 0.17 & 0.37 & 0 & 3 \\
\hline Market geography & 4705 & 3.06 & 1.06 & 0 & 4 \\
\hline Belonging to group & 4705 & 0.59 & 0.49 & 0 & 1 \\
\hline Size & 4705 & 4.55 & 1.27 & 2.99 & 9.91 \\
\hline High technology & 4705 & 0.07 & 0.26 & 0 & 1 \\
\hline Medium high technology & 4705 & 0.21 & 0.41 & 0 & 1 \\
\hline Medium low technology & 4705 & 0.33 & 0.47 & 0 & 1 \\
\hline Low technology & 4705 & 0.37 & 0.48 & 0 & 1 \\
\hline
\end{tabular}




\section{Appendix 3. Correlations}

\begin{tabular}{|c|c|c|c|c|c|c|c|c|c|c|c|c|c|c|c|c|c|c|c|c|c|c|c|}
\hline & (1) & (2) & (3) & (4) & (5) & (6) & (7) & (8) & (9) & (10) & (11) & (12) & (13) & (14) & (15) & (16) & (17) & (18) & (19) & (20) & (21) & (22) & (23) \\
\hline Ecoproduct (1) & 1.00 & & & & & & & & & & & & & & & & & & & & & & \\
\hline Ecoprocess (2) & 0.64 & 1.00 & & & & & & & & & & & & & & & & & & & & & \\
\hline R\&D Cooperation (3) & 0.49 & 0.48 & 1.00 & & & & & & & & & & & & & & & & & & & & \\
\hline Acquisition (4) & 0.44 & 0.55 & 0.43 & 1.00 & & & & & & & & & & & & & & & & & & & \\
\hline External R\&D (5) & 0.40 & 0.34 & 0.48 & 0.33 & 1.00 & & & & & & & & & & & & & & & & & & \\
\hline Market sources (6) & 0.42 & 0.37 & 0.37 & 0.37 & 0.27 & 1.00 & & & & & & & & & & & & & & & & & \\
\hline Institutional sources (7) & 0.14 & 0.13 & 0.19 & 0.10 & 0.18 & 0.12 & 1.00 & & & & & & & & & & & & & & & & \\
\hline Other sources (8) & 0.25 & 0.20 & 0.25 & 0.18 & 0.17 & 0.26 & 0.16 & 1.00 & & & & & & & & & & & & & & & \\
\hline Existing regulations (9) & 0.45 & 0.47 & 0.33 & 0.32 & 0.27 & 0.27 & 0.12 & 0.18 & 1.00 & & & & & & & & & & & & & & \\
\hline Expected regulations (10) & 0.39 & 0.38 & 0.27 & 0.26 & 0.26 & 0.21 & 0.09 & 0.12 & 0.61 & 1.00 & & & & & & & & & & & & & \\
\hline Environmental codes (11) & 0.38 & 0.40 & 0.28 & 0.27 & 0.23 & 0.20 & 0.07 & 0.15 & 0.48 & 0.38 & 1.00 & & & & & & & & & & & & \\
\hline Control procedures (12) & 0.43 & 0.42 & 0.35 & 0.30 & 0.32 & 0.25 & 0.12 & 0.14 & 0.46 & 0.38 & 0.43 & 1.00 & & & & & & & & & & & \\
\hline Public funding (13) & 0.21 & 0.23 & 0.14 & 0.16 & 0.13 & 0.12 & 0.10 & 0.08 & 0.31 & 0.33 & 0.25 & 0.23 & 1.00 & & & & & & & & & & \\
\hline Market demand (14) & 0.41 & 0.39 & 0.28 & 0.26 & 0.22 & 0.23 & 0.08 & 0.14 & 0.42 & 0.41 & 0.44 & 0.32 & 0.24 & 1.00 & & & & & & & & & \\
\hline Market geography (15) & 0.32 & 0.22 & 0.26 & 0.19 & 0.25 & 0.20 & 0.09 & 0.14 & 0.21 & 0.19 & 0.16 & 0.25 & 0.08 & 0.15 & 1.00 & & & & & & & & \\
\hline Cost reduction (16) & 0.43 & 0.45 & 0.30 & 0.30 & 0.23 & 0.21 & 0.09 & 0.15 & 0.45 & 0.38 & 0.49 & 0.40 & 0.28 & 0.41 & 0.21 & 1.00 & & & & & & & \\
\hline Intramural R\&D (17) & 0.62 & 0.48 & 0.51 & 0.42 & 0.42 & 0.45 & 0.15 & 0.28 & 0.34 & 0.30 & 0.27 & 0.37 & 0.15 & 0.29 & 0.37 & 0.35 & 1.00 & & & & & & \\
\hline Internal sources (18) & 0.52 & 0.45 & 0.43 & 0.41 & 0.38 & 0.36 & 0.13 & 0.19 & 0.30 & 0.26 & 0.25 & 0.34 & 0.14 & 0.24 & 0.28 & 0.29 & 0.60 & 1.00 & & & & & \\
\hline Size (19) & 0.39 & 0.33 & 0.34 & 0.22 & 0.35 & 0.23 & 0.13 & 0.14 & 0.35 & 0.33 & 0.27 & 0.48 & 0.16 & 0.25 & 0.38 & 0.31 & 0.39 & 0.34 & 1.00 & & & & \\
\hline Belonging to group (20) & 0.25 & 0.23 & 0.25 & 0.15 & 0.24 & 0.16 & 0.06 & 0.06 & 0.21 & 0.20 & 0.18 & 0.31 & 0.09 & 0.16 & 0.26 & 0.20 & 0.26 & 0.25 & 0.50 & 1.00 & & & \\
\hline $\begin{array}{l}\text { High technology ( } 21) \\
\text { Medium high technology }\end{array}$ & 0.08 & 0.07 & 0.13 & 0.08 & 0.14 & 0.05 & 0.09 & 0.07 & 0.06 & 0.03 & 0.04 & 0.07 & 0.02 & 0.02 & 0.12 & 0.04 & 0.12 & 0.10 & 0.16 & 0.09 & 1.00 & & \\
\hline & 0.19 & 0.11 & 0.11 & 0.07 & 0.13 & 0.11 & 0.04 & 0.04 & 0.13 & 0.15 & 0.11 & 0.16 & 0.02 & 0.11 & 0.25 & 0.09 & 0.19 & 0.17 & 0.13 & 0.13 & -0.15 & 1.00 & \\
\hline Medium low technology (23) & -0.08 & -0.08 & -0.05 & -0.05 & -0.08 & -0.08 & -0.02 & -0.03 & -0.07 & -.06 & -0.07 & -0.10 & -0.02 & -0.03 & -0.14 & -0.06 & -.09 & -0.08 & -0.10 & -0.07 & -0.20 & -0.37 & 1.00 \\
\hline
\end{tabular}




\section{Table 1}

Bivariate Probit results: Effects of different modes of openness

\begin{tabular}{|c|c|c|c|c|}
\hline & \multicolumn{2}{|c|}{ Model 1} & \multicolumn{2}{|c|}{ Model 2} \\
\hline & Ecoproduct & Ecoprocess & Ecoproduct & Ecoprocess \\
\hline \multicolumn{5}{|l|}{ Acquiring } \\
\hline Acquisition & $0.430(0.055)^{* * *}$ & $0.971(0.054)^{* * *}$ & $0.736(0.127)^{* * *}$ & $1.709(0.107)^{* * *}$ \\
\hline External R\&D & $0.151(0.066)^{* *}$ & $-0.035(0.069)$ & $0.725(0.146)^{* * *}$ & $0.150(0.172)$ \\
\hline \multicolumn{5}{|l|}{ Sharing } \\
\hline R\&D cooperation & $0.330(0.060)^{* * *}$ & $0.479(0.061)^{* * *}$ & $0.496(0.132)^{* * *}$ & $0.632(0.138)^{* * *}$ \\
\hline \multicolumn{5}{|l|}{ Sourcing } \\
\hline Market sources & $0.382(0.058)^{* * *}$ & $0.234(0.058)^{* * *}$ & $0.446(0.139)^{* * *}$ & $0.447(0.131)^{* * *}$ \\
\hline Institutional sources & $-0.054(0.157)$ & $0.138(0.159)$ & $0.465(0.401)$ & $0.255(0.517)$ \\
\hline Other sources & $0.162(0.083)^{*}$ & $0.016(0.084)$ & $0.167(0.220)$ & $-0.159(0.243)$ \\
\hline \multicolumn{5}{|c|}{ Moderating role of intramural $R \& D$} \\
\hline Acquisition $\times$ IntramuralR\&D & & & $-0.476(0.142)^{* * *}$ & $-1.123(0.124)^{* * *}$ \\
\hline ExtR\&D×IntramuralR\&D & & & $-0.672(0.161)^{* * *}$ & $-0.152(0.185)$ \\
\hline Cooperation $\times$ IntramuralR $\& D$ & & & $-0.245(0.148)^{*}$ & $-0.279(0.152)^{*}$ \\
\hline SoMarket×IntramuralR\&D & & & $-0.135(0.152)$ & $-0.374(0.145)^{* * *}$ \\
\hline SoInsti $\times$ IntramuralR\&D & & & $-0.572(0.430)$ & $-0.108(0.540)$ \\
\hline SoOther $\times$ IntramuralR\&D & & & $-0.020(0.235)$ & $0.185(0.256)$ \\
\hline \multicolumn{5}{|l|}{ Other supply factors } \\
\hline Intramural R\&D & $1.034(0.065)^{* * *}$ & $0.453(0.062)^{* * *}$ & $1.544(0.102)^{* * *}$ & $1.224(0.091)^{* * *}$ \\
\hline Cost reduction & $0.353(0.062)^{* * *}$ & $0.516(0.060)^{* * *}$ & $0.339(0.062)^{* * *}$ & $0.479(0.059)^{* * *}$ \\
\hline Internal sources & $0.506(0.058)^{* * *}$ & $0.331(0.059)^{* * *}$ & $0.404(0.060)^{* * *}$ & $0.194(0.059)^{* * *}$ \\
\hline \multicolumn{5}{|l|}{ Environmental policy factors } \\
\hline Existing regulations & $0.295(0.070)^{* * *}$ & $0.429(0.068)^{* * *}$ & $0.292(0.070)^{* * *}$ & $0.429(0.067)^{* * *}$ \\
\hline Expected regulations & $0.179(0.080)^{* *}$ & $0.079(0.080)$ & $0.181(0.079)^{* *}$ & $0.082(0.078)$ \\
\hline Environmental codes & $0.170(0.070)^{* *}$ & $0.194(0.070)^{* * *}$ & $0.157(0.069)^{* *}$ & $0.186(0.068)^{* * *}$ \\
\hline Control procedures & $0.196(0.062)^{* * *}$ & $0.247(0.061)^{* * *}$ & $0.181(0.062)^{* * *}$ & $0.232(0.061)^{* * *}$ \\
\hline Public funding & $0.075(0.112)$ & $0.114(0.106)$ & $0.089(0.111)$ & $0.125(0.103)$ \\
\hline \multicolumn{5}{|l|}{ Demand factors } \\
\hline Market demand & $0.494(0.070)^{* * *}$ & $0.329(0.071)^{* * *}$ & $0.478(0.069)^{* * *}$ & $0.326(0.069)^{* * *}$ \\
\hline Market geography & $0.122(0.031)^{* * *}$ & $-0.047(0.027)^{*}$ & $0.124(0.032)^{* * *}$ & $-0.053(0.029)^{*}$ \\
\hline \multicolumn{5}{|l|}{ Other control variables } \\
\hline Size & $0.047(0.026)^{*}$ & $0.0095(0.026)$ & $0.058(0.026)^{* *}$ & $0.021(0.026)$ \\
\hline Belonging to group & $-0.025(0.064)$ & $0.074(0.059)$ & $-0.040(0.066)$ & $0.063(0.062)$ \\
\hline High-technology & $-0.093(0.098)$ & $-0.117(0.102)$ & $-0.041(0.097)$ & $-0.067(0.100)$ \\
\hline High-medium technology & $0.183(0.071)^{* *}$ & $-0.041(0.070)$ & $0.193(0.072)^{* * *}$ & $-0.022(0.070)$ \\
\hline Medium-low technology & $0.0458(0.065)$ & $0.028(0.058)$ & $0.063(0.066)$ & $0.058(0.062)$ \\
\hline Constant & $-2.846(0.132)^{* * *}$ & $-1.901(0.114)^{* * *}$ & $-3.132(0.146)^{* * *}$ & $-2.281(0.124)^{* * * *}$ \\
\hline $\begin{array}{l}\text { Observations } \\
\text { Log pseudolikelihood }\end{array}$ & $\begin{array}{c}4,705 \\
-2933.91\end{array}$ & & $\begin{array}{c}4,705 \\
-2910.00\end{array}$ & \\
\hline$p$-Value & 0.00 & & 0.00 & \\
\hline Rho & $0.028(0.526)$ & & $0.032(0.514)$ & \\
\hline Wald $\chi^{2}$ & 3049.75 & & 3280.94 & \\
\hline
\end{tabular}

Notes: Standard errors are in parentheses.

$* * * p<.01 . * * p<.05 . * p<.1$. 


\section{Table 2}

Bivariate Probit results: Effects of breadth of inbound modes

\begin{tabular}{|c|c|c|c|c|}
\hline \multirow[b]{2}{*}{ VARIABLES } & \multicolumn{2}{|c|}{ Model 3} & \multicolumn{2}{|c|}{ Model 4} \\
\hline & Ecoprocess & Ecoproduct & Ecoprocess & Ecoproduct \\
\hline Breadth & $0.804(0.088)^{* * *}$ & $1.356(0.088)^{* * *}$ & $0.876(0.090)^{* * *}$ & $1.422(0.083)^{* * *}$ \\
\hline Squared Breadth & $-0.137(0.027)^{* * *}$ & $-0.274(0.027)^{* * *}$ & $-0.090(0.028)^{* * *}$ & $-0.188(0.029)^{* * *}$ \\
\hline Breadth $\times$ IntramuralRD & & & $-0.322(0.0608)^{* * *}$ & $-0.508(0.0632)^{* * *}$ \\
\hline Intramural $R \& D$ & $0.973(0.066)^{* * *}$ & $0.250(0.065)^{* * *}$ & $1.414(0.109)^{* * *}$ & $0.938(0.104)^{* * *}$ \\
\hline Observations & 4,705 & 4,705 & 4,705 & 4,705 \\
\hline
\end{tabular}

Notes: Standard errors are in parentheses.

${ }^{* * *} p<.01 .{ }^{* *} p<.05 . * p<.1$.

\section{Table 3}

Summary of hypotheses results

\begin{tabular}{|c|c|c|}
\hline Hypotheses & Supported & $\begin{array}{c}\text { Not } \\
\text { Supported }\end{array}$ \\
\hline $\begin{array}{l}\text { Hla: Inbound innovation acquisition through the purchase of new } \\
\text { machinery is likely to be more associated with ecoprocess than with } \\
\text { ecoproduct innovations. } \\
\text { H1b: Inbound innovation acquisition through external R\&D is likely to } \\
\text { be more associated with ecoproduct than with ecoprocess innovations. }\end{array}$ & $\begin{array}{l}X \\
X\end{array}$ & \\
\hline $\begin{array}{l}\text { H2: Inbound innovation sharing (cooperation) is likely to be more } \\
\text { associated with ecoprocess than with ecoproduct innovations. }\end{array}$ & $\mathrm{X}$ & \\
\hline $\begin{array}{l}\text { H3a: Inbound innovation sourcing from external market sources is likely } \\
\text { to be more associated with ecoproduct than with ecoprocess innovations. }\end{array}$ & $X$ & \\
\hline $\begin{array}{l}\text { H3b: Inbound innovation sourcing from knowledge institutions is likely } \\
\text { to be more associated with ecoproduct than with ecoprocess innovations. }\end{array}$ & & $\mathrm{X}$ \\
\hline $\begin{array}{l}\text { H4: Absorptive capacity positively moderates the relationship between } \\
\text { inbound modes and EI. }\end{array}$ & & $\mathrm{X}$ \\
\hline
\end{tabular}

